\title{
A Novel Decision-Making Approach to Fund Investments Based on Multigranulation Rough Set
}

\author{
Xima Yue $(\mathbb{D}$ and Xiang Su \\ School of Economics and Management, Jiangsu University of Science and Technology, Zhenjiang 212003, China \\ Correspondence should be addressed to Xima Yue; ximayue@126.com
}

Received 11 July 2018; Accepted 2 September 2018; Published 14 October 2018

Guest Editor: Bernardo A. Furtado

Copyright ( 2018 Xima Yue and Xiang Su. This is an open access article distributed under the Creative Commons Attribution License, which permits unrestricted use, distribution, and reproduction in any medium, provided the original work is properly cited.

\begin{abstract}
Fund investment is a hot issue in today's society. How to choose a project for investment is affected by many factors. In view of this problem, this paper starts from the granular computing point of view and combines the multigranulation rough set decisionmaking method to construct a fund investment decision information system; then, the fund investment decision information system is reduced under different thresholds, and the decision rules are extracted through reduction. And from the aspects of decision accuracy and rule accuracy, the rules are analyzed. Finally, decision rules are used to give the decision of the fund investment project. This study provides a new approach to fund management.
\end{abstract}

\section{Introduction}

Fund investment management [1] is a hot issue in today's society. How to choose a better one from some of the possible fund projects or to find some direction from the existing successful fund project before investment is a problem that every decision maker needs to think about. At present, many scholars have studied how to carry out project selection and malpractice from the pension fund industry and social insurance industry [2-6].

In order to enable investors to better invest in projects, many scholars have carried out many researches on investment methods in recent years. Lu [7] uses mathematical methods to analyze the major Reynolds index, SHARP index, Jansen index, and M2 index, which are mainly used in the performance evaluation of the fund, and deduces the relationship between each other by mathematical methods. It also expounds the conditions for the use of indicators in the performance evaluation of funds. Peng [8] systematically introduced the theories and methods of performance evaluation of open-end funds and summarized the research results of fund performance evaluation both at home and abroad. Then, according to the scientific, systematic, and feasible principles, we select 9 indicators that can reflect the performance level of the open-end fund and use the analytic hierarchy process to construct the system of the performance evaluation of the open-end fund in China. Then, we evaluated the index factors of sample funds in the sample period, respectively. Finally, combined with fuzzy comprehensive evaluation method and grey comprehensive evaluation method, we get the overall evaluation results of an openend fund performance. From the quantitative and qualitative point of view, $\mathrm{Xu}$ [9] selected the VaR method combining the GARCH model and the fuzzy comprehensive evaluation method using the analytic hierarchy process to further construct the risk assessment system of China's open fund.

Rough set theory $[10,11]$ is a mathematical method proposed by Professor Pawlak in 1982 to effectively analyze and deal with inaccurate, inconsistent, and incomplete information. After nearly thirty years of development, rough set theory has been widely used in the fields of pattern recognition, machine learning, decision analysis, knowledge acquisition, and data mining. The classical rough set is an equivalent class derived from a single undiscernible twoelement relation on a domain. The following and upper approximation sets are used to rough the unknown concept. Granular computing is a new discipline with rapid development. It integrates many theoretical research achievements 
such as rough set, fuzzy set, and artificial intelligence. At present, rough set theory has become an important tool for granular computing. Literatures [12-14] from the angle of granular computing (parallel multiple grain structures), the knowledge particles (equivalent classes) derived from a single indiscernible two-element relation, are analyzed to approximate the inadequacies of the rough sets of the unknown concepts. Furthermore, the concept of multigranulation rough sets is proposed. An optimistic multigranulation rough set and a pessimistic multigranulation rough set model are given. The Pawlak rough set is extended from a single grain structure to a number of granular structures, and it is proved that the classic rough set model of Pawlak is a special case of the multigranularity rough set. In addition, many researchers have extended the multigranularity rough set. Xu et al. have done a lot of work on multigranulation rough sets [15-20]. Yang and others studied the multigranularity rough set [21-25] based on incomplete information system, test cost sensitivity, and hierarchical structure.

In order to solve the problem of project investment fund, this paper constructs the fund investment decision information system from the perspective of granular computing and combined with multigranular rough set decision method. Then reduce the information table, extract the rules from the simplified information table, and perform the rule analysis. Finally, the decision conclusions of the fund investment are given. The main contributions of this article are as follows:

(1) This paper proposes a method for constructing a project fund investment decision information system, which is the premise that we use rough sets to solve project investment problems

(2) In this paper, the generalized multigranularity rough set model is used to reduce the fund project information system, and then the rules are extracted on the simplified information system. Finally, the fund investment decision is given from these rules

The remaining structure of this paper is shown as follows: in the second part, the related knowledge of multigranularity rough sets is introduced. In the third part, the cleaning information system of the fund investment project is constructed. In the fourth part, the fund investment decision based on the multigranularity rough set is studied. Finally, the conclusion is given in the fifth part.

\section{Preliminaries}

The section recalls necessary concepts and preliminaries required in the sequel of our work. Detailed description of the theory can be found in $[12,13,26-29]$.

An information system with decisions is an ordered quadruple $\mathscr{I}=(U, A \cup D, F, G)$, where

(i) $U=\left\{x_{1}, x_{2}, \cdots, x_{n}\right\}$ is a nonempty finite set of objects

(ii) $A \cup D$ is a nonempty finite attribute set (iii) $A=\left\{a_{1}, a_{2}, \cdots, a_{p}\right\}$ denotes the set of condition attributes

(iv) $D=\left\{d_{1}, d_{2}, \cdots, d_{q}\right\}$ denotes the set of decision attributes and $A \cap D=\varnothing$

(v) $F=\left\{f_{k} \mid U \longrightarrow V_{k}, k \leq p\right\}, f_{k}(x)$ is the value of $a_{k}$ on $x \in U, V_{k}$, the domain of $a_{k}, a_{k} \in A$

(vi) $G=\left\{g_{k^{\prime}} \mid U \longrightarrow V_{k^{\prime}}, k^{\prime} \leq q\right\}, g_{k^{\prime}}(x)$ is the value of $d_{k^{\prime}}$ on $x \in U, V_{k^{\prime}}$, the domain of $d_{k^{\prime}}, d_{k^{\prime}} \in D$

In an information system, the equivalence class of an object with respect to an attribute subset of $A$ is a granularity from the viewpoint of granular computing. A partition of the universe is a granular structure. Rough set proposed by Pawlak is a single granularity rough set model, and the granular structure in this model is induced by the indiscernibility relation of the attribute set. In general, the above cases cannot always be satisfied or required in practical problems. In the three cases referred in [12], there are limitations in single granularity rough set for addressing practical problems with multiple partitions, and multigranulation rough set can now be used to effectively solve these problems. Under those circumstances, we must describe a target concept through multiple binary relations on the universe according to user's requirements or targets of problem solving. In the literatures [12, 13, 26, 27], to apply rough set theory to practical problems widely, multigranulation rough set model has been studied based on multiple equivalence relations.

Let $\mathscr{I}=(U, A \cup D, F, G)$ be an information system, $X \subseteq$ $U$ and $P=\left\{P_{1}, P_{2}, \cdots, P_{t}\right\} P_{i} \subseteq A(i=1,2, \cdots, l)$. Then $P_{i}$ or $U / P_{i}$ is referred to as a granularity. The equivalence class of an object $x$ with respect to $P_{i}$ is defined as

$$
[x]_{P i}=\{y \in U \mid f(x, a)=f(y, a)\}, \quad\left(a \in P_{i}\right) .
$$

The lower and upper approximation sets of $X$ with respect to single $P_{i}$ are defined as follows:

$$
\begin{aligned}
& \underline{P_{i}}(X)=\left\{x \in U \mid[x]_{P_{i}} \subseteq X\right\}, \\
& \overline{P_{i}}(X)=\left\{x \in U \mid[x]_{P_{i}} \bigcap X \neq \varnothing\right\} .
\end{aligned}
$$

Considering further studies on multigranulation rough set, we now review the two basic forms of multigranulation rough set model.

Definition 1 (see [12]). Let $\mathscr{I}=(U, A \cup D, F, G)$ be an information system, $X \subseteq U$ and $P=\left\{P_{1}, P_{2}, \cdots, P_{t}\right\}, P_{i} \subseteq A(i=1$, $2, \cdots, l)$. The optimistic multigranulation lower and upper approximation sets of $X$ with respect to single $P$ are defined as follows:

$$
\begin{aligned}
& \underline{P}(X)_{O M}=\left\{x \in U \mid \vee\left([x]_{P_{i}} \subseteq X\right), i \leq l\right\}, \\
& \bar{P}(X)_{O M}=\left\{x \in U \mid \wedge\left([x]_{P_{i}} \bigcap X \neq \varnothing\right), i \leq l\right\}
\end{aligned}
$$


where "V" means the logical operator "or," which represents that the alternative conditions are satisfied, and " $\wedge$ " means the logical operator "and," which represents that all of the conditions are satisfied.

The set $X$ is definable if and only if $\underline{P}(X)_{O M}=\bar{P}(X)_{O M}$. Otherwise, $X$ is rough. $\underline{P}(X)_{O M}$ and $\bar{P}(X)_{O M}$ are referred to as optimistic lower and upper approximation sets, respectively.

From the above definition, the operators " $\vee$ " and " $\wedge$ " can be exchanged between the optimistic lower approximation set and the optimistic upper approximation set. Corresponding to optimistic multigranulation rough set, pessimistic multigranulation rough set model can be defined in the following.

Definition 2 (see [12]). Let $\mathscr{I}=(U, A \cup D, F, G)$ be an information system, $X \subseteq U$ and $P=\left\{P_{1}, P_{2}, \cdots, P_{t}\right\}, P_{i} \subseteq A$ $(i=1,2, \cdots, l)$. The optimistic multigranulation lower and upper approximation sets of $X$ with respect to single $P$ are defined as follows:

$$
\begin{aligned}
& \underline{P}(X)_{\mathrm{PM}}=\left\{x \in U \mid \wedge\left([x]_{P_{i}} \subseteq X\right), i \leq l\right\}, \\
& \bar{P}(X)_{\mathrm{PM}}=\left\{x \in U \mid \vee\left([x]_{P_{i}} \bigcap X \neq \varnothing\right), i \leq l\right\} .
\end{aligned}
$$

The set $X$ is definable when and only when $\underline{P}(X)_{\mathrm{PM}}=$ $\bar{P}(X)_{\mathrm{PM}}$. Otherwise, $X$ is rough. $\underline{P}(X)_{\mathrm{PM}}$ and $\bar{P}(X)_{\mathrm{PM}}$ are referred to as pessimistic lower and upper approximation sets, respectively.

The uncertainty of a concept in a multigranulation rough set model is also due to the existence of a boundary region. The greater the boundary of a concept is, the lower its accuracy is, and the coarser the concept is. Similar to the measures in the Pawlak rough set model, the accuracy and roughness measures in optimistic multigranulation rough set and pessimistic multigranulation rough set were defined in the same way [12]. As generalizations of the Pawlak rough set model, we only show the relations among optimistic multigranulation rough set, pessimistic multigranulation rough set, and single granularity rough set in the following.

Proposition 1 (see [12]). Let $\mathscr{I}=(U, A \cup D, F, G)$ be an information system, $X \subseteq U$ and $P=\left\{P_{1}, P_{2}, \cdots, P_{t}\right\}, P_{i} \subseteq A$ $(i=1,2, \cdots, l)$. The following properties hold:

(1) $\underline{P}(X)_{\mathrm{OM}}=\bigcup_{i=1}^{l} \underline{P_{i}}(X)$
(2) $\bar{P}(X)_{\mathrm{OM}}=\bigcap_{i=1}^{l} \overline{P_{i}}(X)$
(3) $\underline{P}(X)_{\mathrm{PM}}=\bigcap_{i=1}^{l} \underline{P_{i}}(X)$
(4) $\bar{P}(X)_{\mathrm{PM}}=\bigcup_{i=1}^{l} \bar{P}_{i}(X)$

(5) $\underline{P}(X)_{\mathrm{PM}} \subseteq \underline{P}(X)_{\mathrm{OM}}$

(6) $\bar{P}(X)_{\mathrm{OM}} \subseteq \bar{P}(X)_{\mathrm{PM}}$

In addition, there are many related properties as well as proof, please refer to [12, 28].

In order to express generalized multigranulation rough sets, we first introduce a characteristic function, which is called support feature function.

Definition 3 (see [30]). Let $\mathscr{I}=(U, A \cup D, F, G)$ be an information system, $X \subseteq U$ and $P=\left\{P_{1}, P_{2}, \cdots, P_{t}\right\}, P_{i} \subseteq A$ $(i=1,2, \cdots, l)$, suppose

$$
S_{X}^{P_{i}}(x)=\left\{\begin{array}{ll}
1, & {[x]_{P_{i}} \subseteq X} \\
0, & \text { else }
\end{array} \quad(i \leq l) .\right.
$$

$S_{X}^{P_{i}}(x)$ is called $x$ 's support feature function for $X$, which is used to describe the inclusion relation between equivalence class $[x]_{P_{i}}$ and concept $X$, which indicates whether object $x$ accurately supports $X$ by $P_{i}$.

The optimistic multigranular rough set and the pessimistic multigranular rough set are generalizations of two multigranular rough set models. We will propose a new multigranular rough set model with the parameter $\beta \in(0.5,1]$. We have introduced this parameter to implement the conceptual description of objects that support the concept at the most granular levels. Objects that may portray the concept are ignored below the corresponding level. The new model is expressed as follows.

Definition 4 (see [30]). Let $\mathscr{I}=(U, A \cup D, F, G)$ be an information system, $X \subseteq U$ and $P=\left\{P_{1}, P_{2}, \cdots, P_{t}\right\}, P_{i} \subseteq A(i=1$, $2, \cdots, l), S_{X}^{P_{i}}(x)$ is called $x$ 's support feature function for $X$. For any $\beta \in(0.5,1]$, the lower approximation and upper approximation of $X$ for $P$ are defined as follows:

$$
\begin{aligned}
& \underline{P}(X)_{\beta}=\left\{x \in U \mid \frac{\sum_{i=1}^{l} S_{X}^{P_{i}}(x)}{l} \geq \beta\right\}, \\
& \bar{P}(X)_{\beta}=\left\{x \in U \mid \frac{\sum_{i=1}^{l}\left(1-S_{\sim X}^{P_{i}}(x)\right)}{l}>1-\beta\right\} .
\end{aligned}
$$

The set $X$ is definable if $\underline{P}(X)_{\beta}=\bar{P}(X)_{\beta}$; otherwise, $X$ is a rough set. We denote this generalized multigranulation rough set model as GMGRS, and $\beta$ as the information level for $P$.

The multigranulation rough set is a generalization of the classical rough set. Since several attributes in the information system can have different effects on the decision-making 
effect, when these effects cannot be performed simultaneously, but separately and independently, we cannot use classical rough set theory to treat these attributes as a whole through an indistinguishable relationship for system reduction and rule extraction. Therefore, according to the general process of rough set decision, we can get the specific steps of multigranular rough set decision and provide a theoretical model for decision analysis of fund project investment in multigranular environment.

\section{Construction of Decision Information System for Fund Investments}

Fund has become an increasingly important source of financing for people. For a decision maker, one may need to adopt a better one from some possible fund projects or find some directions from existing successful fund projects before investing. How to do it? We will propose a novel decision-making fund investments based on multigranulation rough set. This section mainly focuses to build fund investment decision information system.

The flow chart of our multigranulation decision-making model for fund investment is shown in Figure 1.

As can be seen from the flow chart, the investment decision system model based on the multigranulation rough set fund is constructed according to the following steps.

Step 1. Select condition attributes of the decision system. Before investing in the fund project, we first carry out the essential project evaluation for each project. In this paper, we through the project interviews, questionnaires, and other methods to determine project evaluation factors, which are Market environment, Science and technology level, Education level, Management level, and Cultural level, respectively. There are five aspects to measure every fund project. These evaluation factors consists of a conditional attribute set of the fun investment decision-making system based on multigranulation rough sets.

Step 2. Determine the value of the every condition attribute. According to the performance of market environment level, science and technology level, education level, management level, and culture level, a comprehensive overall evaluation of the items was conducted to be evaluated. In order to study conveniently, we only have a small research. So, we can simplify attribute values, which is divided into A, B, C, D, and $\mathrm{E}$ five grades for each factor. Moreover, five grades $\mathrm{A}$, B, C, D, and E present mainly outstanding, good, general, poor, and very poor, respectively.

Step 3. Determine the decision attribute of the decision system. According to the above analysis, the decision attribute is divided into good and common decision results. Of course, depending on the situation, the decision attribute can also be set to three or more attribute values.

Step 4. Knowledge representation of the decision system based on multigranulation rough set. According to the knowledge of multigranulation rough sets and the above analysis, we

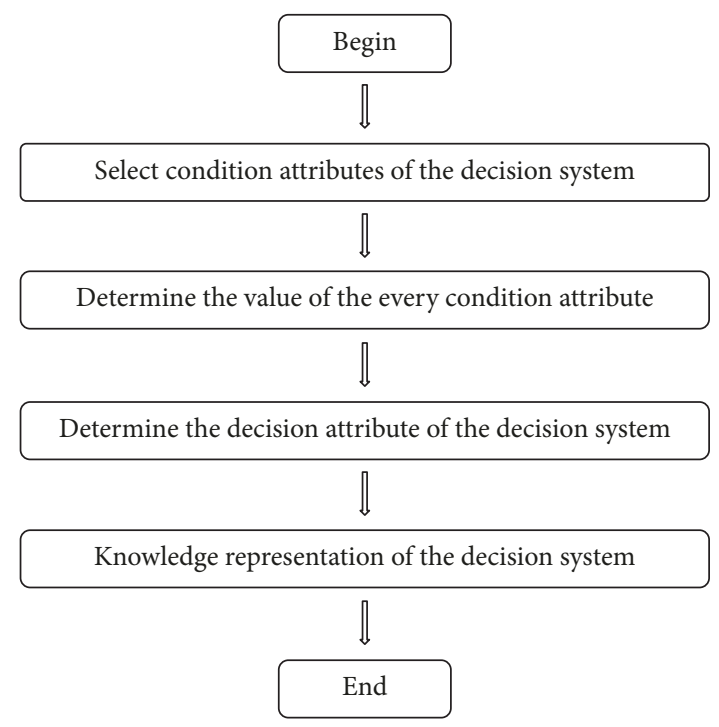

FIgURE 1: The flow chart of multigranulation decision-making model for fund investment.

TABLE 1: A fund investment information decision system.

\begin{tabular}{ccccccc}
\hline$U$ & $P_{1}$ & $P_{2}$ & $P_{3}$ & $P_{4}$ & $P_{5}$ & $d$ \\
\hline$x_{1}$ & $\mathrm{~A}$ & $\mathrm{~A}$ & $\mathrm{C}$ & $\mathrm{B}$ & $\mathrm{C}$ & $\mathrm{G}$ \\
$x_{2}$ & $\mathrm{~B}$ & $\mathrm{~A}$ & $\mathrm{C}$ & $\mathrm{C}$ & $\mathrm{D}$ & $\mathrm{Co}$ \\
$x_{3}$ & $\mathrm{C}$ & $\mathrm{D}$ & $\mathrm{E}$ & $\mathrm{B}$ & $\mathrm{D}$ & $\mathrm{Co}$ \\
$x_{4}$ & $\mathrm{~B}$ & $\mathrm{~B}$ & $\mathrm{~A}$ & $\mathrm{~B}$ & $\mathrm{~A}$ & $\mathrm{G}$ \\
$x_{5}$ & $\mathrm{~A}$ & $\mathrm{~B}$ & $\mathrm{D}$ & $\mathrm{A}$ & $\mathrm{B}$ & $\mathrm{G}$ \\
$x_{6}$ & $\mathrm{C}$ & $\mathrm{C}$ & $\mathrm{C}$ & $\mathrm{D}$ & $\mathrm{E}$ & $\mathrm{Co}$ \\
\hline
\end{tabular}

regard these five conditional attributes as five granularities, i.e., $P_{1}=\left\{a_{1}\right\}, P_{2}=\left\{a_{2}\right\}, P_{3}=\left\{a_{3}\right\}, P_{4}=\left\{a_{4}\right\}, P_{5}=\left\{a_{5}\right\}$. At the same time, we randomly selected six experts. These experts are familiar with every project comparison by a long period of research and questionnaire. Thus, the evaluation result can be thought to constitute a small expert system.

Through this evaluation form, we obtained 6 valid data and formed 6 objects into the decision-making information system in Table 1.

Remark. We mainly check the reduction and decision rule by designing multiple granularity rough set decision steps, and we can get more granular rough set decision-making application. In the paper, we do not set on a large scale data in detail and do not set testing for the rules, which will be our future research work.

\section{Decision Making for Fund Investments Based on Multigranulation Rough Set}

In this section, based on the previous theories, the fund investment decisions are made with multigranulation rough sets. Firstly, generalized multigranulation rough set model 
is used to fund investment decision-making information system, and then some important rules are extracted based on the reduction of the information system. Finally, results of fund investment decision can be given from the obtained conclusion.

Starting from the data of the fund investment decisionmaking information system in Table 1, funds are classified according to different granularities. The classification results are as follows:

$$
\begin{aligned}
& \frac{U}{P_{1}}=\left\{\left\{x_{1}, x_{5}\right\},\left\{x_{2}, x_{4}\right\},\left\{x_{3}, x_{6}\right\}\right\}, \\
& \frac{U}{P_{2}}=\left\{\left\{x_{1}, x_{2}\right\},\left\{x_{3}\right\},\left\{x_{4}, x_{5}\right\},\left\{x_{6}\right\}\right\}, \\
& \frac{U}{P_{3}}=\left\{\left\{x_{1}, x_{2}, x_{6}\right\},\left\{x_{3}\right\},\left\{x_{4}\right\},\left\{x_{5}\right\}\right\}, \\
& \frac{U}{P_{4}}=\left\{\left\{x_{1}, x_{3}, x_{4}\right\},\left\{x_{2}\right\},\left\{x_{5}\right\},\left\{x_{6}\right\}\right\}, \\
& \frac{U}{P_{5}}=\left\{\left\{x_{1}\right\},\left\{x_{2}, x_{3}\right\},\left\{x_{4}\right\},\left\{x_{5}\right\},\left\{x_{6}\right\}\right\}, \\
& \frac{U}{d}=\left\{\left\{x_{1}, x_{4}, x_{5}\right\},\left\{x_{2}, x_{3}, x_{6}\right\}\right\} .
\end{aligned}
$$

If we take information level $\beta=0.7(0.6<\beta \leq 1)$ and $\beta=0.6(0.5<\beta \leq 0.6)$, then we can obtain the support feature matrix tables of lower approximation and upper approximation for every decision class in Tables 2-5.

So, we can calculate the lower approximation and upper approximation of $D_{1}$ and $D_{2}$.

$$
\begin{aligned}
& \underline{P}\left(D_{1}\right)_{0.7}=\left\{x_{5}\right\}, \\
& \bar{P}\left(D_{1}\right)_{0.7}=\left\{x_{1}, x_{2}, x_{4}, x_{5}\right\}, \\
& \underline{P}\left(D_{2}\right)_{0.7}=\left\{x_{3}, x_{6}\right\}, \\
& \bar{P}\left(D_{1}\right)_{0.7}=\left\{x_{1}, x_{2}, x_{3}, x_{4}, x_{6}\right\}, \\
& \underline{P}\left(D_{1}\right)_{0.6}=\left\{x_{4}, x_{5}\right\}, \\
& \bar{P}\left(D_{1}\right)_{0.6}=\left\{x_{1}, x_{2}, x_{4}, x_{5}\right\}, \\
& \underline{P}\left(D_{2}\right)_{0.6}=\left\{x_{3}, x_{6}\right\}, \\
& \bar{P}\left(D_{2}\right)_{0.6}=\left\{x_{1}, x_{2}, x_{3}, x_{6}\right\} .
\end{aligned}
$$

\begin{tabular}{|c|c|c|}
\hline & $D_{1}$ & $D_{2}$ \\
\hline$x_{1}$ & 0 & $0)$ \\
\hline$x_{2}$ & 0 & 0 \\
\hline$x_{3}$ & 0 & 1 \\
\hline$x_{4}$ & 0 & 0 \\
\hline$x_{5}$ & 1 & 0 \\
\hline$x_{6}$ & 0 & 1) \\
\hline
\end{tabular}

In keeping the classification unchanged, all the reductions of the decision-making information system are obtained by MATLAB calculation as follows.

\begin{tabular}{|c|c|c|}
\hline & $D_{1}$ & $D_{2}$ \\
\hline$x_{1}$ & 1 & $1)$ \\
\hline$x_{2}$ & 1 & 1 \\
\hline$x_{3}$ & 0 & 1 \\
\hline$x_{4}$ & 1 & 1 \\
\hline$x_{5}$ & 1 & 0 \\
\hline$x_{6}$ & 0 & 1) \\
\hline
\end{tabular}

If we take information level $\beta=0.7(0.6<\beta \leq 1)$, then the reduction is $\left\{a_{1}, a_{2}, a_{3}, a_{4}, a_{5}\right\}$. Moreover, if we take information level $\beta=0.6(0.5<\beta \leq 0.6)$, then the reduction

\begin{tabular}{|c|c|c|}
\hline & $D_{1}$ & $D_{2}$ \\
\hline$x_{1}$ & ( 1 & 1) \\
\hline$x_{2}$ & 1 & 1 \\
\hline$x_{3}$ & 0 & 1 \\
\hline$x_{4}$ & 1 & 0 \\
\hline$x_{5}$ & 1 & 0 \\
\hline$x_{6}$ & 0 & 1) \\
\hline
\end{tabular}
is $\left\{a_{1}, a_{2}, a_{3}, a_{5}\right\}$ and $\left\{a_{2}, a_{3}, a_{4}, a_{5}\right\}$.

In the next, we extract the rules from two cases according to the reduction obtained above and give the

\begin{tabular}{|c|c|c|}
\hline & $D_{1}$ & $D_{2}$ \\
\hline$x_{1}$ & 0 & 0 \\
\hline$x_{2}$ & 0 & 0 \\
\hline$x_{3}$ & 0 & 1 \\
\hline$x_{4}$ & 1 & 0 \\
\hline$x_{5}$ & 1 & 0 \\
\hline$x_{6}$ & 0 & 1) \\
\hline
\end{tabular}
quantitative results for the decision precision and rule precision of the rules.
TABLE 2: The support feature matrix table of lower approximation $(\beta=0.7)$.

TABLE 3: The support feature matrix table of upper approximation $(\beta=0.7)$.

TABLE 4: The support feature matrix table of upper approximation $(\beta=0.6)$.

TABLE 5: The support feature matrix table of lower approximation $(\beta=0.6)$.

Case 1. The information level is $\beta=0.7(0.6<\beta \leq 1)$, and the reduction is $\left\{a_{1}, a_{2}, a_{3}, a_{4}, a_{5}\right\}$.

In this case, rule can be carried out in accordance with the system. In fact, each object is a decision rule, 
and the information cannot be simplified attributes in the system. So, we extract the rules directly, and the rules are in the following.

$$
\begin{aligned}
& r_{1}:\left(P_{1}, A\right) \wedge\left(P_{2}, A\right) \wedge\left(P_{3}, C\right) \wedge\left(P_{4}, B\right) \wedge\left(P_{5}, C\right) \longrightarrow(d, G,(0.6,1]), \\
& r_{2}:\left(P_{1}, B\right) \wedge\left(P_{2}, A\right) \wedge\left(P_{3}, C\right) \wedge\left(P_{4}, C\right) \wedge\left(P_{5}, D\right) \longrightarrow(d, C o,(0.6,1]), \\
& r_{3}:\left(P_{1}, C\right) \wedge\left(P_{2}, D\right) \wedge\left(P_{3}, E\right) \wedge\left(P_{4}, B\right) \wedge\left(P_{5}, D\right) \longrightarrow(d, C o,(0.6,1]), \\
& r_{4}:\left(P_{1}, B\right) \wedge\left(P_{2}, B\right) \wedge\left(P_{3}, A\right) \wedge\left(P_{4}, B\right) \wedge\left(P_{5}, A\right) \longrightarrow(d, G,(0.6,1]), \\
& r_{5}:\left(P_{1}, A\right) \wedge\left(P_{2}, B\right) \wedge\left(P_{3}, D\right) \wedge\left(P_{4}, A\right) \wedge\left(P_{5}, B\right) \longrightarrow(d, G,(0.6,1]), \\
& r_{6}:\left(P_{1}, C\right) \wedge\left(P_{2}, C\right) \wedge\left(P_{3}, C\right) \wedge\left(P_{4}, D\right) \wedge\left(P_{5}, E\right) \longrightarrow(d, C o,(0.6,1]) .
\end{aligned}
$$

These rules are always valid and unique in decision information system of Table 1 . Moreover, we can find that the decision accuracy of each rule is all $1 / 3$ and the rule accuracy is 1 . In this case, the evaluation requires all the information of a fund project, which is not very useful for us to simplify the decision-making process and deal with unknown information.

Case 2. The information level is $\beta=0.6(0.5<\beta \leq 0.6)$, and the reduction is $\left\{a_{1}, a_{2}, a_{3}, a_{5}\right\}$ and $\left\{a_{2}, a_{3}, a_{4}, a_{5}\right\}$.

In the case, from the reductions, we can find that the decision system can be presented by partial not all attributes.

Thus, the decision system can be simplified in the following two decision tables which are Tables 6 and 7.

From Table 6, we can have some rules as follows:

$$
\begin{aligned}
& r_{1}:\left(P_{1}, A\right) \wedge\left(P_{2}, A\right) \wedge\left(P_{3}, C\right) \wedge\left(P_{5}, C\right) \longrightarrow(d, G,(0.5,0.6]), \\
& r_{2}:\left(P_{1}, B\right) \wedge\left(P_{2}, A\right) \wedge\left(P_{3}, C\right) \wedge\left(P_{5}, D\right) \longrightarrow(d, C o,(0.5,0.6]), \\
& r_{3}:\left(P_{1}, C\right) \wedge\left(P_{2}, D\right) \wedge\left(P_{3}, E\right) \wedge\left(P_{5}, D\right) \longrightarrow(d, C o,(0.5,0.6]), \\
& r_{4}:\left(P_{1}, B\right) \wedge\left(P_{2}, B\right) \wedge\left(P_{3}, A\right) \wedge\left(P_{5}, A\right) \longrightarrow(d, G,(0.5,0.6]), \\
& r_{5}:\left(P_{1}, A\right) \wedge\left(P_{2}, B\right) \wedge\left(P_{3}, D\right) \wedge\left(P_{5}, B\right) \longrightarrow(d, G,(0.5,0.6]), \\
& r_{6}:\left(P_{1}, C\right) \wedge\left(P_{2}, C\right) \wedge\left(P_{3}, C\right) \wedge\left(P_{5}, E\right) \longrightarrow(d, C o,(0.5,0.6]) .
\end{aligned}
$$

From Table 7, we can have some rules as follows:

$$
\begin{aligned}
& r_{7}:\left(P_{2}, A\right) \wedge\left(P_{3}, C\right) \wedge\left(P_{4}, B\right) \wedge\left(P_{5}, C\right) \longrightarrow(d, G,(0.5,0.6]), \\
& r_{8}:\left(P_{2}, A\right) \wedge\left(P_{3}, C\right) \wedge\left(P_{4}, C\right) \wedge\left(P_{5}, D\right) \longrightarrow(d, C o,(0.5,0.6]), \\
& r_{9}:\left(P_{2}, D\right) \wedge\left(P_{3}, E\right) \wedge\left(P_{4}, B\right) \wedge\left(P_{5}, D\right) \longrightarrow(d, C o,(0.5,0.6]), \\
& r_{10}:\left(P_{2}, B\right) \wedge\left(P_{3}, A\right) \wedge\left(P_{4}, B\right) \wedge\left(P_{5}, A\right) \longrightarrow(d, G,(0.5,0.6]), \\
& r_{11}:\left(P_{2}, B\right) \wedge\left(P_{3}, D\right) \wedge\left(P_{4}, A\right) \wedge\left(P_{5}, B\right) \longrightarrow(d, G,(0.5,0.6]), \\
& r_{12}:\left(P_{2}, C\right) \wedge\left(P_{3}, C\right) \wedge\left(P_{4}, D\right) \wedge\left(P_{5}, E\right) \longrightarrow(d, C o,(0.5,0.6]) .
\end{aligned}
$$

TABLE 6: Fund investment decision system after the reduction (I).

\begin{tabular}{cccccc}
\hline$U$ & $P_{1}$ & $P_{2}$ & $P_{3}$ & $P_{5}$ & $d$ \\
\hline$x_{1}$ & $\mathrm{~A}$ & $\mathrm{~A}$ & $\mathrm{C}$ & $\mathrm{C}$ & $\mathrm{G}$ \\
$x_{2}$ & $\mathrm{~B}$ & $\mathrm{~A}$ & $\mathrm{C}$ & $\mathrm{D}$ & $\mathrm{Co}$ \\
$x_{3}$ & $\mathrm{C}$ & $\mathrm{D}$ & $\mathrm{E}$ & $\mathrm{D}$ & $\mathrm{Co}$ \\
$x_{4}$ & $\mathrm{~B}$ & $\mathrm{~B}$ & $\mathrm{~A}$ & $\mathrm{~A}$ & $\mathrm{G}$ \\
$x_{5}$ & $\mathrm{~A}$ & $\mathrm{~B}$ & $\mathrm{D}$ & $\mathrm{B}$ & $\mathrm{G}$ \\
$x_{6}$ & $\mathrm{C}$ & $\mathrm{C}$ & $\mathrm{C}$ & $\mathrm{E}$ & $\mathrm{Co}$ \\
\hline
\end{tabular}

TABLE 7: Fund investment decision system after the reduction (II).

\begin{tabular}{lccccc}
\hline$U$ & $P_{2}$ & $P_{3}$ & $P_{4}$ & $P_{5}$ & $d$ \\
\hline$x_{1}$ & $\mathrm{~A}$ & $\mathrm{C}$ & $\mathrm{B}$ & $\mathrm{C}$ & $\mathrm{G}$ \\
$x_{2}$ & $\mathrm{~A}$ & $\mathrm{C}$ & $\mathrm{C}$ & $\mathrm{D}$ & $\mathrm{Co}$ \\
$x_{3}$ & $\mathrm{D}$ & $\mathrm{E}$ & $\mathrm{B}$ & $\mathrm{D}$ & $\mathrm{Co}$ \\
$x_{4}$ & $\mathrm{~B}$ & $\mathrm{~A}$ & $\mathrm{~B}$ & $\mathrm{~A}$ & $\mathrm{G}$ \\
$x_{5}$ & $\mathrm{~B}$ & $\mathrm{D}$ & $\mathrm{A}$ & $\mathrm{B}$ & $\mathrm{G}$ \\
$x_{6}$ & $\mathrm{C}$ & $\mathrm{C}$ & $\mathrm{D}$ & $\mathrm{E}$ & $\mathrm{Co}$ \\
\hline
\end{tabular}

As a result of our data on a smaller scale, the reduction of information system data has no duplication, so that we get 12 decision rules. When the data size is larger, reduction can make a lot of duplicate data merging, effectively reduce the number of decision rules, and improve the decision accuracy and precision of rules.

According to the calculation, the accuracy of the above 12 decision rules is $1 / 6$ and the accuracy of the rules is 1 . Although the decision-making accuracy is reduced, the rule accuracy does not decrease. So, we can have that reduction that simplifies the test of the data validation rules; decision conclusion can be obtained without a large scale of data validation.

From the rules obtained above, the conclusion of the decision making for fund investments can be got about the decision information system in Table 1. According to the representation form of decision rules, each decision result is shown in Table 8 . The symbol means that the corresponding value is arbitrary, that is, any value taken under the specified conditions in the table has no influence on the decision result indicated in the table.

\section{Conclusions}

In this paper, a multigranulation rough set decision method is used to construct the fund investment decision information system; then, the fund investment decision information system is reduced at different thresholds, the decision rules are extracted by reduction and the rules are analyzed, and finally the decision rules are given using fund investment 
TABLE 8: Decision results of the fund investment information system.

\begin{tabular}{|c|c|c|c|c|}
\hline $\begin{array}{l}\text { The serial } \\
\text { number }\end{array}$ & Decision factors & $\begin{array}{l}\text { Decision } \\
\text { results }\end{array}$ & $\begin{array}{l}\text { Decision } \\
\text { accuracy }\end{array}$ & $\begin{array}{c}\text { Information } \\
\text { level } \beta\end{array}$ \\
\hline 1 & $a_{1}$-outstanding, $a_{2}$-outstanding, $a_{3}$-general, $a_{4}$-good, $a_{5}$-general & $G$ & 1 & $(0.6,1]$ \\
\hline 2 & $a_{1}$-good, $a_{2}$-outstanding, $a_{3}$-general, $a_{4}$-general, $a_{5}$-poor & Co & 1 & $(0.6,1]$ \\
\hline 3 & $a_{1}-$ general, $a_{2}-$ poor, $a_{3}$-very poor, $a_{4}-$ good, $a_{5}-$ poor & Co & 1 & $(0.6,1]$ \\
\hline 4 & $a_{1}-$ good, $a_{2}$-good, $a_{3}$-outstanding, $a_{4}$-good, $a_{5}$-outstanding & G & 1 & $(0.6,1]$ \\
\hline 5 & $a_{1}$-outstanding, $a_{2}$-good, $a_{3}$-poor, $a_{4}$-outstanding, $a_{5}$-good & G & 1 & $(0.6,1]$ \\
\hline 6 & $a_{1}$-general, $a_{2}$-general, $a_{3}$-general, $a_{4}$-poor, $a_{5}$-very poor & Co & 1 & $(0.6,1]$ \\
\hline 7 & $a_{1}$-outstanding, $a_{2}$-outstanding, $a_{3}$-general, $a_{4}-^{*}, a_{5}$-general & G & 1 & $(0.5,0.6]$ \\
\hline 8 & $a_{1}$-good, $a_{2}$-outstanding, $a_{3}$-general, $a_{4}-^{*}, a_{5}$-poor & Co & 1 & $(0.5,0.6]$ \\
\hline 9 & $a_{1}$-general, $a_{2}$-poor, $a_{3}$-very poor, $a_{4}-^{*}, a_{5}$-poor & Co & 1 & $(0.5,0.6]$ \\
\hline 10 & $a_{1}$-good, $a_{2}$-good, $a_{3}$-outstanding, $a_{4}-^{*}, a_{5}$-outstanding & G & 1 & $(0.5,0.6]$ \\
\hline 11 & $a_{1}$-outstanding, $a_{2}$-good, $a_{3}$-poor, $a_{4}-^{*}, a_{5}$-good & G & 1 & $(0.5,0.6]$ \\
\hline 12 & $a_{1}$-general, $a_{2}$-general, $a_{3}$-general, $a_{4}-^{*}, a_{5}$-very poor & Co & 1 & $(0.5,0.6]$ \\
\hline 13 & $a_{1}-^{*}, a_{2}$-outstanding, $a_{3}$-general, $a_{4}$-good, $a_{5}$-general & G & 1 & $(0.5,0.6]$ \\
\hline 14 & $a_{1}-^{*}, a_{2}$-outstanding, $a_{3}$-general, $a_{4}$-general, $a_{5}$-poor & Co & 1 & $(0.5,0.6]$ \\
\hline 15 & $a_{1}$ - $^{*}, a_{2}-$ poor, $a_{3}$-very poor, $a_{4}-$ good, $a_{5}$-poor & Co & 1 & $(0.5,0.6]$ \\
\hline 16 & $a_{1}-^{*}, a_{2}$-good, $a_{3}$-outstanding, $a_{4}$-good, $a_{5}$-outstanding & $G$ & 1 & $(0.5,0.6]$ \\
\hline 17 & $a_{1}-^{*}, a_{2}-$ good, $a_{3}-$ poor, $a_{4}$-outstanding, $a_{5}$-good & $G$ & 1 & $(0.5,0.6]$ \\
\hline 18 & $a_{1}-^{*}, a_{2}$-general, $a_{3}$-general, $a_{4}$-poor, $a_{5}$-very poor & $C_{O}$ & 1 & $(0.5,0.6]$ \\
\hline
\end{tabular}

decision making. This study provides a new approach to fund management, enriching the application of multigranulation rough sets.

\section{Data Availability}

The data used to support the findings of this study are included within the article.

\section{Conflicts of Interest}

The authors declare no conflict of interest.

\section{Authors' Contributions}

$\mathrm{XY}$ is the principal investigator of this work. He performed the experiments and wrote this manuscript. XS contributed to the framework and provided several suggestions for improving the quality of this manuscript. All authors revised and approved the publication.

\section{References}

[1] Y. Li, Fund Investment Management, Economic Science Press, 2002.

[2] D. Blake, A. G. Rossi, A. Timmermann, I. Tonks, and R. Wermers, "Decentralized investment management: evidence from the pension fund industry," The Journal of Finance, vol. 68, no. 3, pp. 1133-1178, 2013.

[3] D. L. Luskin and L. G. Tint, Investment Fund Management Method and System, 2002.
[4] A. Andonov, P. Eichholtz, and N. Kok, "Intermediated investment management in private markets: evidence from pension fund investments in real estate," Journal of Financial Markets, vol. 22, pp. 73-103, 2015.

[5] Z. Wei and Y. Lin, Investment Management Mode of Social Insurance Fund and Getting Rid of the Predicament, 2014, Reform.

[6] Y. Zhang, "Analysis of China's social security fund investment management under the background of financial crisis," Science and Technology Economy Market, vol. 31, no. 1, pp. 106-107, 2016.

[7] Z. Lu, "Analysis of the relationship between performance evaluation indicators of securities investment funds," Economic Mathematics, vol. 22, no. 3, pp. 235-239, 2005.

[8] J. Peng, Research on Performance Evaluation of Open Fund in China Based on Fuzzy Mathematics, Jiangxi University of Science and Technology, 2012.

[9] X. Xu, Research on the Risk Assessment of Open End Funds in China - Based on the Application of VaR-GARCH Model and Fuzzy Mathematics Method, Hefei Polytechnic University, 2015.

[10] Z. Pawlak, "Rough sets," International Journal of Computer \& Information Sciences, vol. 11, no. 5, pp. 341-356, 1982.

[11] Z. Pawlak, "Rudiments of rough sets," Information Sciences, vol. 177, no. 1, pp. 3-27, 2007.

[12] Y. Qian, J. Liang, Y. Yao, and C. Dang, "MGRS: a multigranulation rough set," Information Sciences, vol. 180, no. 6, pp. 949-970, 2010.

[13] Y. Qian, J. Liang, and C. Dang, "Incomplete multigranulation rough set," IEEE Transactions on Systems, Man, and Cybernetics - Part A: Systems and Humans, vol. 40, no. 2, pp. 420-431, 2010. 
[14] Y. Qian, J. Liang, and W. Wei, "Pessimistic rough decision," in Proceedings of the 2nd International Workshop on Rough Sets Theory, pp. 440-449, Zhoushan, China, 2010.

[15] W. Xu, W. Sun, X. Zhang, and W. Zhang, "Multiple granulation rough set approach to ordered information systems," International Journal of General Systems, vol. 41, no. 5, pp. 475-501, 2012.

[16] W. Xu, Q. Wang, and S. Luo, "Multi-granulation fuzzy rough sets," Journal of Intelligent \& Fuzzy Systems, vol. 26, no. 3, pp. 1323-1340, 2014.

[17] W. Xu, Q. Wang, and X. Zhang, "Multi-granulation fuzzy rough sets in a fuzzy tolerance approximation space," International Journal of Fuzzy Systems, vol. 13, no. 4, pp. 246-259, 2011.

[18] W. Xu, Q. Wang, and X. Zhang, "Multi-granulation rough sets based on tolerance relations," Soft Computing, vol. 17, no. 7, pp. 1241-1252, 2013.

[19] W. Xu and W. Li, "Granular computing approach to two-way learning based on formal concept analysis in fuzzy datasets," IEEE Transactions on Cybernetics, vol. 46, no. 2, pp. 366379, 2016.

[20] W. Li and W. Xu, "Multigranulation decision-theoretic rough set in ordered information system," Fundamenta Informaticae, vol. 139, no. 1, pp. 67-89, 2015.

[21] X. Yang, Y. Qi, X. Song, and J. Yang, “Test cost sensitive multigranulation rough set: model and minimal cost selection," Information Sciences, vol. 250, no. 11, pp. 184-199, 2013.

[22] X. Yang, Y. Qi, H. Yu, X. Song, and J. Yang, "Updating multigranulation rough approximations with increasing of granular structures," Knowledge-Based Systems, vol. 64, no. 1, pp. 59-69, 2014.

[23] X. Yang, "Hierarchical structures on multigranulation spaces," Journal of Computer Science and Technology, vol. 27, no. 6, pp. 1169-1183, 2012.

[24] X. Yang, "On multigranulation rough sets in incomplete information system," International Journal of Machine Learning and Cybernetics, vol. 3, no. 3, pp. 223-232, 2012.

[25] L. Wang, X. Yang, and J. Yang, "A new incomplete multi granularity rough set," Journal of Nanjing University (Natural Science), vol. 48, no. 4, pp. 436-444, 2012.

[26] Y. Qian, J. Liang, and C. Dang, "Knowledge structure, knowledge granulation and knowledge distance in a knowledge base," International Journal of Approximate Reasoning, vol. 50, no. 1, pp. 174-188, 2009.

[27] Y. Yao, "Information granulation and rough set approximation," International Journal of Intelligent Systems, vol. 16, no. 1, pp. 87-104, 2001.

[28] Y. Qian and J. Liang, "Rough set method based on multigranulations," in 2006 5th IEEE International Conference on Cognitive Informatics, pp. 297-304, Beijing, China, July 2006.

[29] W. Xu, X. Zhang, and Q. Wang, "A generalized multigranulation rough set approach," in Bio-Inspired Computing and Applications. ICIC 2011, Lecture Notes in Computer Science, D. S. Huang, Y. Gan, P. Premaratne, and K. Han, Eds., pp. 681-689, Springer, Berlin, Heidelberg, 2011.

[30] W. Xu, W. Li, and X. Zhang, "Generalized multigranulation rough sets and optimal granularity selection," Granular Computing, vol. 2, no. 4, pp. 271-288, 2017. 


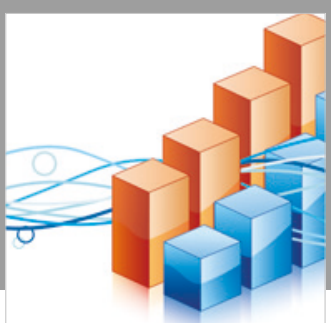

Advances in

Operations Research

\section{-n-m}
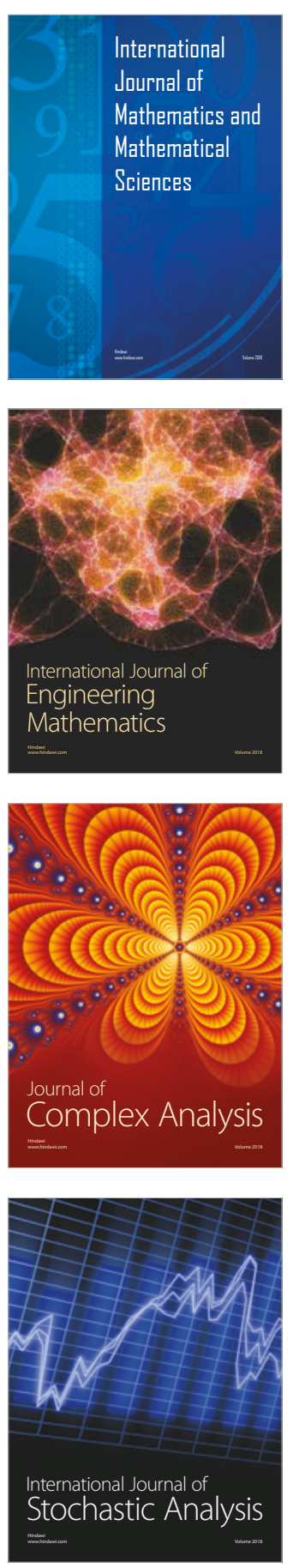
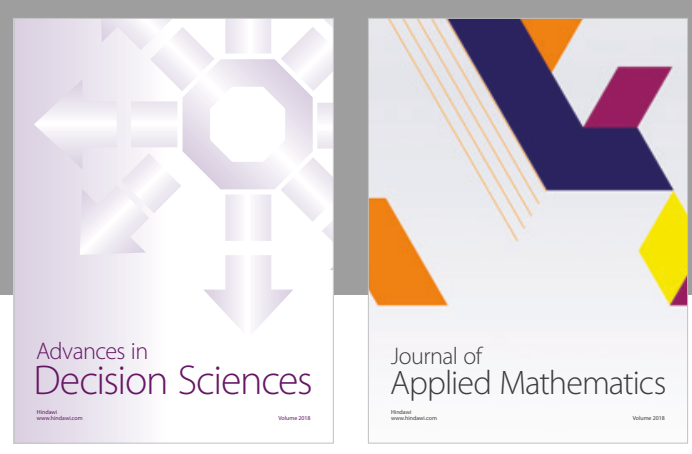

Journal of

Applied Mathematics
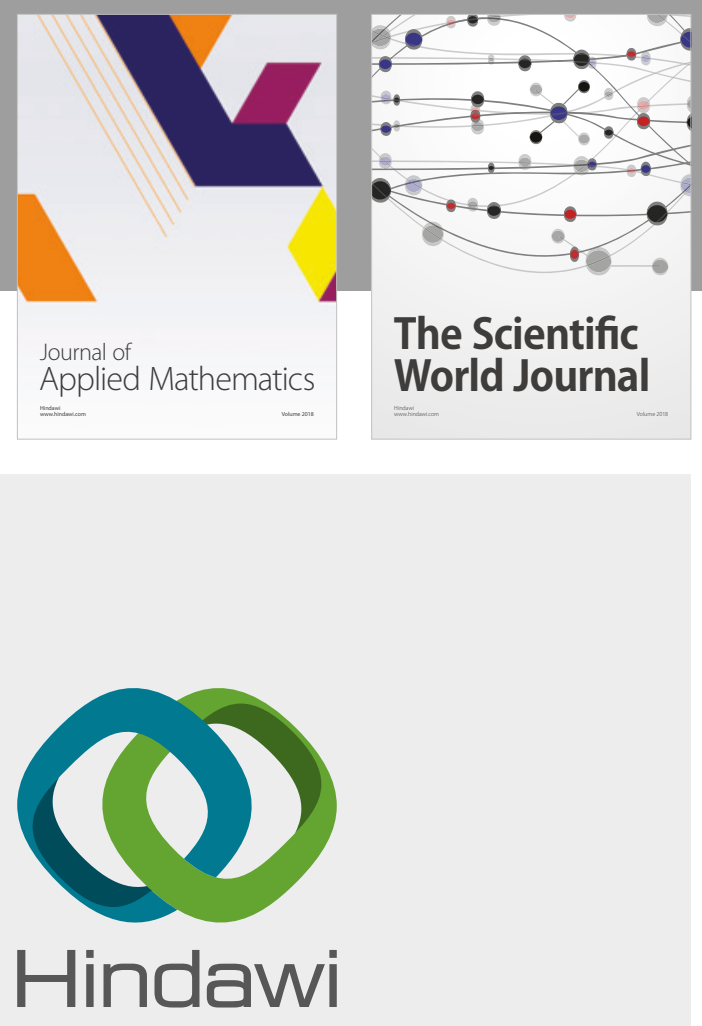

Submit your manuscripts at

www.hindawi.com

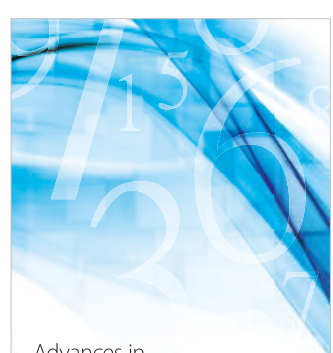

Advances in
Numerical Analysis
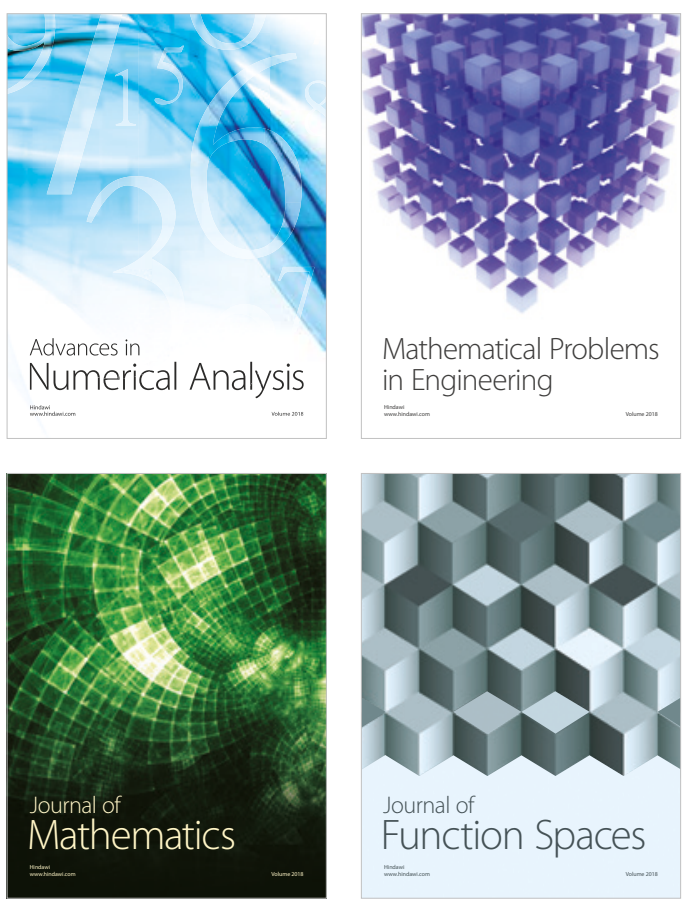

Mathematical Problems in Engineering

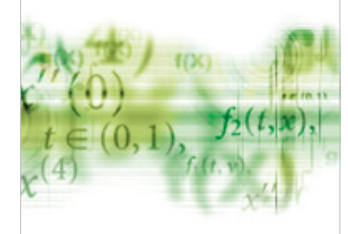

International Journal of

Differential Equations

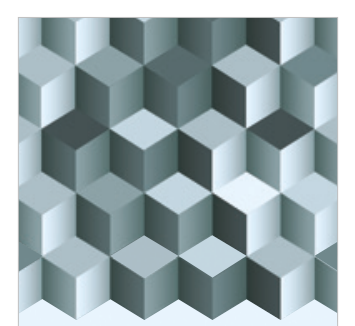

Journal of

Function Spaces
The Scientific

World Journal

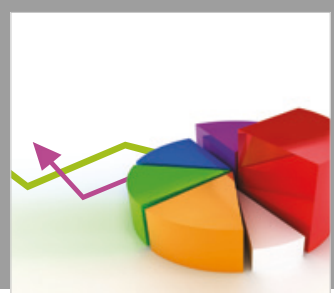

Journal of

Probability and Statistics
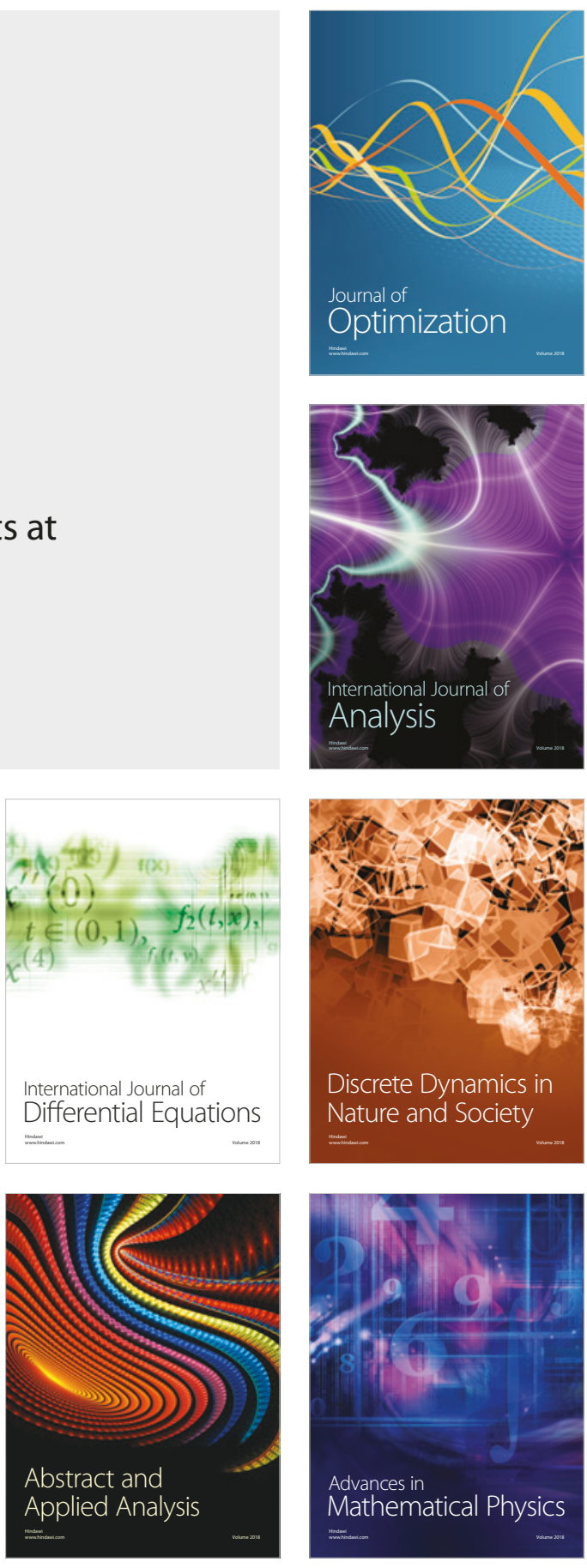